The Journal of

Thoracic and Cardiovascular

Surgery

Vol 127, No. 2, February 2004

\title{
New-onset postoperative atrial fibrillation: A riddle wrapped in a mystery inside an enigma
}

Adam E. Saltman, MD, PhD

An appendix of 24 key references is available online.

See related article on page 511 .
From the Division of Cardiothoracic Surgery, Departments of Surgery and Physiology, University of Massachusetts, Worcester, Mass.

Received for publication March 26, 2003; revisions requested April 8, 2003; accepted for publication April 24, 2003.

Address for reprints: Adam E. Saltman, MD, PhD, Division of CT Surgery, 55 Lake Avenue North, S3-747, Worcester, MA 01655 (E-mail: adam.saltman@umassmed. edu).

J Thorac Cardiovasc Surg 2004;127:311-3 $0022-5223 / \$ 30.00$

Copyright $\odot 2004$ by The American Association for Thoracic Surgery

doi:10.1016/j.jtcvs.2003.04.004

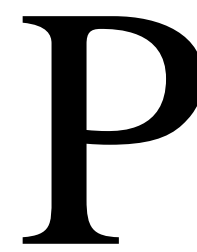

ostoperative new-onset atrial fibrillation (PAF) remains the most common and vexing problem confronting cardiac surgeons. It afflicts as many as $40 \%$ of patients undergoing coronary and valve surgery and has been refractory to many attempted methods of prevention, both pharmacologic and nonpharmacologic. In this issue of the Journal, Melo and colleagues ${ }^{1}$ have described a simple, quick, and effective adjunct procedure applied at the time of the operation that appears to halve the incidence of PAF.

Although these authors have elegantly described a method that resulted in a 58\% reduction in the incidence of PAF, what is most interesting is that neither this study nor any of those that have preceded it over the last 40 years has demonstrated a prophylaxis that completely prevents PAF. Why is this? Most likely it is our poor understanding of the mechanism underlying PAF: we simply do not know what causes this phenomenon and therefore have been unable to make meaningful and effective progress against it.

A review of electrophysiologic basics should prove helpful. Atrial fibrillation is a reentrant arrhythmia. For any reentrant arrhythmia to occur, 2 conditions must exist: there must be an initiating event that sets up the reentrant circuit, and there must be a substrate capable of maintaining the arrhythmia. First, let us consider initiation.

Initiation of reentry occurs when excitable tissue demonstrates unidirectional conduction block and slow conduction. Unidirectional block means that an excitation wave can no longer penetrate tissue in an orthograde manner yet can progress through it in a retrograde direction. This is typically the result of prolonged refractoriness as the excitation wave encounters cells that have not yet fully recovered excitability. Slow conduction indicates that the progress of an excitation wave is hindered long enough to permit abnormal tissue to recover excitability, usually setting the stage for retrograde reentry of the excitation wave. This is indicated in Figure 1, a classical example of reentry occurring in the end branches of a Purkinje fiber as it ramifies onto a strand of ventricular muscle. This can also occur in normal atrial tissue, as shown in Figure 2, which has many natural ultrastructural branches and joinings.

Can reentry initiate in the postsurgical atrium? Unidirectional conduction block is not difficult to demonstrate because there is a rather large degree of dispersion of refractoriness, even in normal tissue. ${ }^{2,3}$ It is therefore not difficult to imagine how a properly timed impulse might encounter refractory tissue in some patches of tissue and block, whereas other areas would be fully excitable and conduct. Frequent premature atrial contractions and bursts of atrial tachycardia are known to precede bouts of $\mathrm{PAF}^{4}$ and are the likely agents that set up unidirectional block. An interesting question for Melo and colleagues is whether ventral cardiac denervation 


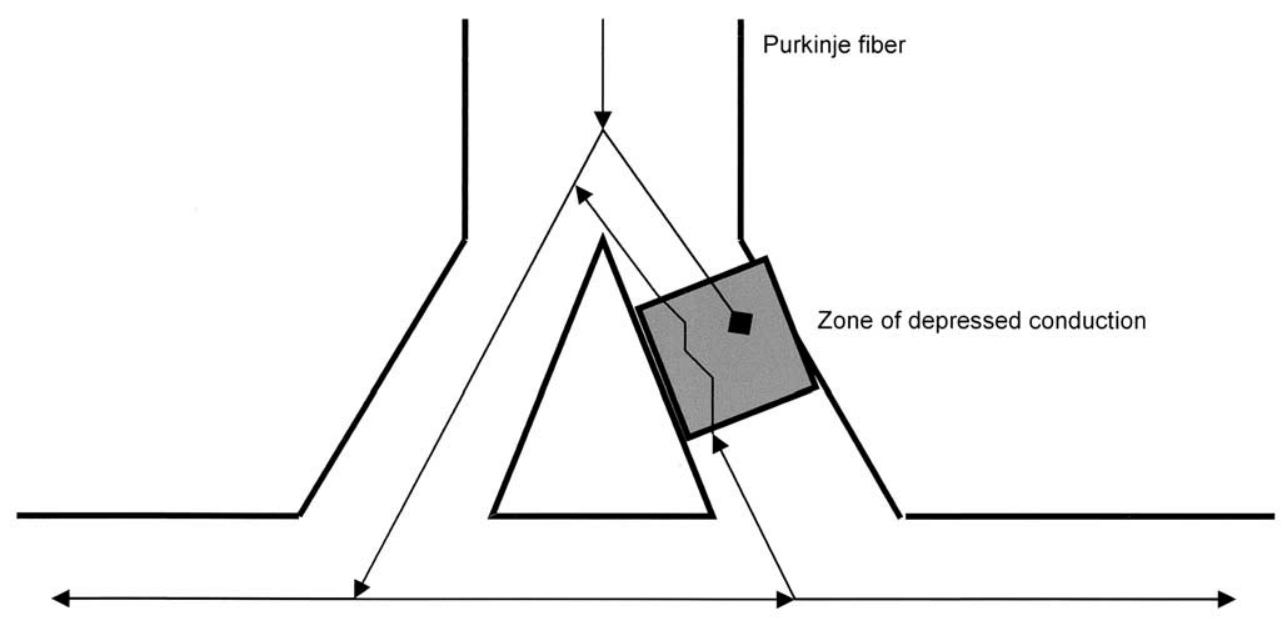

Ventricular muscle fiber

Figure 1. Reentry in the end strand of a Purkinje fiber.

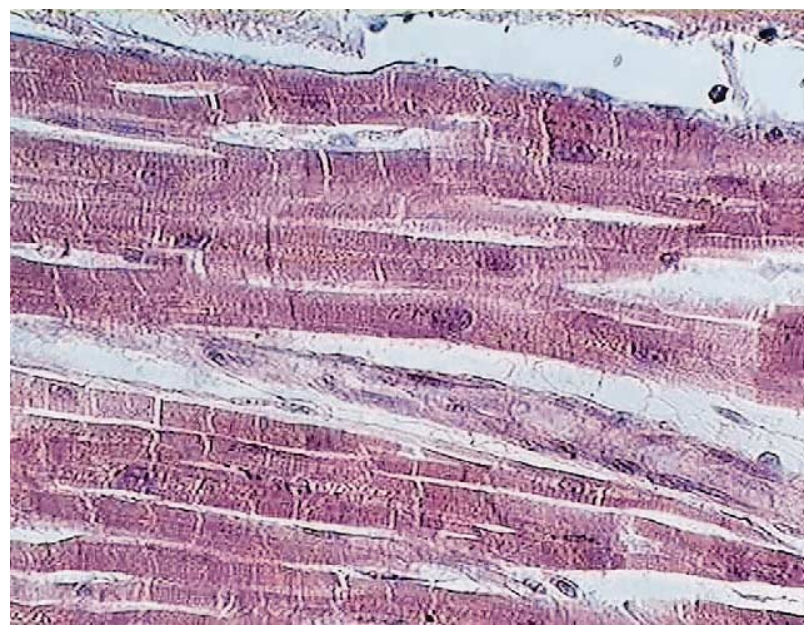

Figure 2. Normal atrial muscle demonstrating multiple branches and joinings.

altered the incidence of premature contractions, which might have been an important salutary effect of their procedure.

Slow conduction, which results from a decrease in the degree of cell-cell coupling, a diminution in the rapid inward sodium current $\mathrm{I}_{\mathrm{Na}}$, is quite unusual in normal atrial tissue. Recently, as shown in Figure 3, we have demonstrated that the inflammatory mediator arachidonic acid can reversibly depress conduction up to $60 \%$ less than baseline in otherwise normal canine and human atrial tissues. ${ }^{5}$ This suggests that the inflammatory state that appears after the operation might in fact alter the underlying atrial electrophysiology in a way that slow conduction might appear.
This is supported by the findings of several studies that have shown that inflammatory markers, although generally increased after cardiopulmonary bypass, are particularly increased in those patients with PAF. ${ }^{6}$

But initiation is not sufficient; once PAF appears, it must be maintained. For PAF to self-perpetuate, the excitation wavelength of the reentrant circuit must be small enough to fit within the physical confines of the affected tissue. Excitation wavelength, defined in centimeters as the product of conduction velocity (in centimeters per second) and refractory period (in seconds), typically ranges from 14 to $18 \mathrm{~cm}$ in the normal atrium. However, it has been shown in the chronically fibrillating atrium that conduction velocity is normal, yet the refractory period is greatly shortened. ${ }^{7}$ As shown above in Figure 3, we have already shown that inflammation decreases conduction velocity in normal atrial tissue. ${ }^{5}$ But further analysis of Figure 3 reveals that this effect was seen only in the direction transverse to the muscle fiber long axis; there was no effect parallel to the long axis. This suggested to us that there was a change only in transverse cell-cell coupling rather than a change in the global properties of either depolarizing sodium ion currents or repolarizing potassium currents. In support of this idea, we have also demonstrated that the topical application of steroidal and nonsteroidal anti-inflammatory drugs can prevent fibrillation in an animal model of sterile talc pericarditis. ${ }^{8}$ Exactly which agent of the inflammatory cascade is to blame and exactly by what mechanism remains yet unknown.

The mechanism by which the method of Melo and colleagues ${ }^{1}$ prevents PAF is not clear, and the authors mention that our knowledge about the type of axons destroyed by 


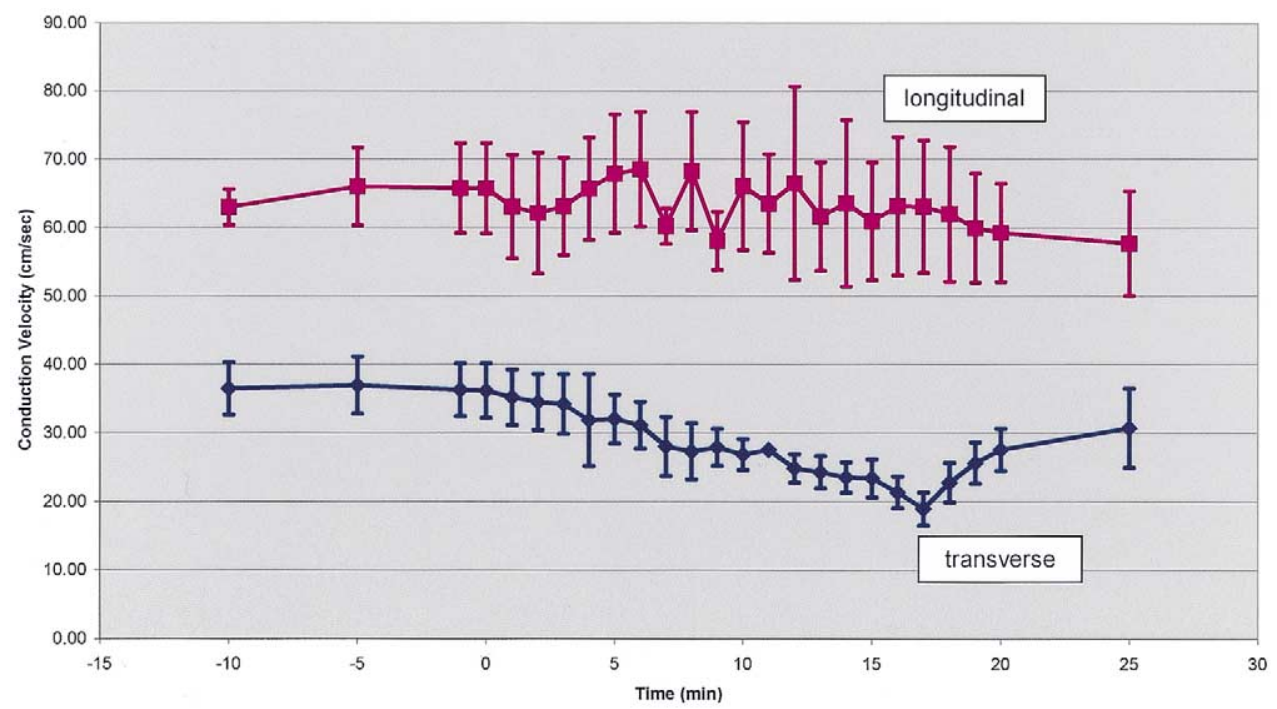

Figure 3. Arachidonic acid reversibly decreases conduction along the fiber axis.

their procedure is quite limited. It is logical to expect, however, that ventral cardiac denervation produces a cardiac sympathectomy because the importance of sympathetic outflow has been highlighted as a possible cause of PAF. ${ }^{9}$ Of course, it is possible that ventral denervation results in a protective parasympathectomy because vagal stimulation (or acetylcholine infusion) has been used for many years in the laboratory to produce atrial fibrillation.

In summary, PAF likely results from postsurgical changes in the atrium that render it susceptible to both the initiation and maintenance of a reentrant arrhythmia. The causes are still not completely defined, although inflammatory changes are certainly suspect. The ventral cardiac denervation technique of Melo and colleagues ${ }^{1}$ appears to be easy, quick, safe, and effective at reducing the incidence of PAF, without the addition of new or harmful drugs to the postoperative regimen. Elucidation of its exact mechanism of action will have to await a better understanding of the underlying pathophysiology of this disease.

\section{References}

1. Melo J, Voigt P, Sonmez B, Ferreira M, Abecasis M, Rebocho M, et al. Ventral cardiac denervation reduces the incidence of atrial fibrillation after coronary artery bypass grafting. J Thorac Cardiovasc Surg. 2003; 127:511-6.

2. Janse MJ. Why does atrial fibrillation occur? Eur Heart J. 1997;18: C12-8.

3. Rensma Pl, Allessie MA, Lammers WJ, Bonke FI, Schalij MJ. Length of excitation wave and susceptibility to reentrant atrial arrhythmias in normal conscious dogs. Circ Res. 1988;62:395-410.

4. Frost L, Christiansen EH, Molgaard H, Jacobsen CJ, Allermand H, Thomsen PE. Premature atrial beat eliciting atrial fibrillation after coronary artery bypass grafting. J Electrocardiol. 1995;28:297-305.

5. Saltman AE, Tselentakis EV, Gaudette GR, Krukenkamp IB. Inflammation and atrial fibrillation: arachidonic acid decreases atrial conduction velocity in a fiber orientation dependent manner. Circulation. 2002;106(suppl):II-344.

6. Chung MK, Martin DO, Sprecher D, Wazni O, Kanderian A, Carnes CA, et al. C-reactive protein elevation in patients with atrial arrhythmias: inflammatory mechanisms and persistence of atrial fibrillation. Circulation. 2001;104:2886-91.

7. Allessie MA, Wijffels MC, Dorland R. Mechanisms of pharmacologic cardioversion of atrial fibrillation by Class I drugs. J Cardiovasc Electrophysiol. 1998;9(suppl):S69-77.

8. Saltman AE, Chandry J, Gaudette GR, Murtha JJ, Krukenkamp IB. Topical application of anti-inflammatory drugs prevents postoperative atrial fibrillation in a canine model. Surg Forum. 2000;51:76-8.

9. Kalman JM, Munawar M, Howes LG, Louis WJ, Buxton BF, Gutteridge $\mathrm{G}$, et al. Atrial fibrillation after coronary artery bypass grafting is associated with sympathetic activation. Ann Thorac Surg. 1995;60: 1709-15. 